of epilepsy now past?' Now, he can find the answers to these and similar questions in this monograph, answers based not on anecdotal evidence but upon a large series of cases carefully studied and assessed.

The importance of information of this kind is known by some of the results. For instance, if a patient with a closed head injury does not have epilepsy within the first week, is not unconscious for more than 24 hours and does not have a depressed fracture or a hæmatoma, the chances of him developing late epilepsy are only about $1 \%$. But if epilepsy occurs within the first week the chances rise to $28 \%$, and if the early epilepsy is associated with a depressed fracture the chances became $50 \%$. An overall figure for the chances of late epilepsy after closed head injury is, therefore, of little value. Prognosis for medical or legal purposes must be based on an accurate assessment of the factors involved in the injury, and the weight to be given to the various factors can be found in this book. The author has done a great service in producing this monograph.

\section{Illustrated Obstetrics for Midwives}

J. M. Holmes, M.D., M.B., B.S., M.R.C.o.G. Pp. viii + I16, with 90 figures. London: Butterworth. 1962. $15 s$.

It is difficult to see why this book was produced. This sort of thing has been better done before. Although the photographs have been touched up and outlined, they are very woolley and cannot compare with those in other textbooks. There is a fair amount of text, remarkably free from errors in the typescript. This is a synopsis of some of the aspects of obstetrics, but a number of the views put forward are at variance with general opinion in the country, nor are definitions of obstetrical terms accurate. Post-partum hæmorrhage, for instance, may be abnormal in amount or type; shaving the patient and the giving of an enema before labour are often the most unpleasant experiences the patient undergoes during her confinement and are best avoided; there is a long description of Heyns' decompression suit, surely an unnecessary feature in a book in which the puerperium is not mentioned; many proprietary preparations are mentioned by name; it is unwise to cover the abdomen during the third stage of labour; there is confusion in the description of postpartum hæmorrhage and, in the delivery of abnormal positions of the head, Lovset's manœuvre is wrongly described.

Before this book can be recommended as suitable for pupil midwives, it will need to be radically revised.

\section{Wound Healing}

Proceedings of a Symposium organized by Smith and Nephew Research Ltd., Hunsdon, Hertfordshire, and held at the Royal College of Surgeons of England. Edited by D. SlOME, M.A., PH.D., M.B., CH.B. Pp. $94+$ xi. Oxford, London, New York, Paris: Pergamon Press. 196r. 30s.

This book comprises the nine papers contributed to a symposium held in November, 1959, at the Royal College of Surgeons of England, together with an introduction by the Editor, Professor Slome. Professor Slome has wisely not included verbatim reports of the discussions that these papers evoked at the time from the participants. However, the text of the various contributions has been modified by the incorporation in many instances of new material, and of the important points made in such discussions.

Many aspects of wound healing are covered, by established experts in their field. Basic scientific in- vestigation is represented by the articles on the control of mitotic activity in the skin, the mechanism of wound contraction, the physical chemistry of collagen, and the use of tissue cultures and of the transparent chamba: technique in the study of wound healing. The finft four contributions are concerned more directly wit clinical problems such as the properties of wounct dressings, the tensile strength of healing incisions aponeurosis, and the management of large skin defects especially in burns.

Everyone who is engaged in clinical surgery shouf benefit, and would certainly derive much intellectu stimulation and enjoyment, from reading this books. The printing and illustrations are excellent, and tife price reasonable. The organizers of the symposiun Smith and Nephew Research Ltd., are to be congratulated upon this permanent record of their fruitfut conception.

Medical Genetics 1958-r960: An Annotated Revie VICTOR A. McKusick, M.D., and contributots: Pp. 534, illustrated. St. Louis: The C. V. Mosl

Co. London: Henry Kimpton. 196r. ro8s. 6dA

It has always been a little confusing to know in what category to place 'medical genetics'. The name seenis to imply that there is a special subject here, distinct frofo human genetics. However, as a descriptive title for the present collection of annotated reviews, the name wil not mislead. Books, journals, symposia and article medical and scientific, published during three years, are included if they are likely to be of interest to cliniciares and medical research workers in any way concerned with genetics. The growth of the subject matter is indicafed by the number of pages devoted to references: I 1958,25 in 1959 and more than 31 in 1960.

The book is intended to be useful to those who fig tit difficult to keep up with the wealth of present literature. Naturally the coverage is not exhaustive, bu it is very extensive and particularly significant relation to inborn errors of metabolism and chromosom 8 aberrations. Information on such topics as consare guinity, incidence statistics and quantitative genetics 8 less complete.

Much of the material in the book is reprinted from annotations which have appeared in the fournal of Chronic Diseases and they originated in the Journal Clu偾 of Johns Hopkins University School of Medicine: These descriptions are set out in the form of numbered paragraphs. The effect of all this is most peculiar and. suggests a series of stop press news items. The arranges ment makes the use of the combined index easy. There. is, however, no authors' index: there are simply three lists of references in alphabetical order which are nof combined. They sometimes are incomplete and workers. should be warned that, if, in the future, too many of them co-operate in essential parts of a research project they will end up as anonymous 'co-authors' of a pape

The actual items vary from single-line notes (e.g. \$165 'Crone and Bergin described Gaucher's disease ino identical twins') to articles two or three pages long, like $\$ 507$ on hypertension or $\$ 775$ on Factor VIII (onfy indexed under 'hæmophilia'); $\$ 825$ on Marfan's synv drome seems to be the longest of all. The reviews are frequently critical and the reader's interest is sustaine or provoked by constructive as well as destructive comments.

This is not a book to be carried about and used as $\cong$ text. It is essentially a reference book for the library shelf. Nevertheless a compilation like this of reviews may constitute a snare because it provides too facile a approach to knowledge. It tempts the reader to negleç to read the original papers and form his own judgmen $\overline{1}$ 